\title{
Incidence of trauma related stress fractures and shin splints in male and female army recruits: retrospective case study
}

\author{
M A Macleod, A S Houston, L Sanders, C Anagnostopoulos
}

The Ministry of Defence's equal opportunities policy, which was introduced in 1993, means that female recruits to army training regiments have been exposed to the same rigorous, physically demanding exercise as men. We noticed a fourfold increase in referrals between 1994 and 1996 and decided to investigate whether this reflected increased referral of women.

\section{Subjects, methods, and results}

Although radiography is the main diagnostic tool for detecting bone trauma, radionuclide bone scanning is more effective at showing stress fractures, shin splints, and covert fractures. ${ }^{12}$

We studied the bone scans of all recruits of an army training regiment who were referred with suspected trauma from 1 April 1995 to 31 March 1997. During this time 4222 recruits (3367 men and 855 women) carried out basic fitness training and were assessed at the regiment.

On referral each patient was assessed to determine the site of injury and for the symptoms and signs of bone pain, tenderness, and swelling. A gamma camera was used to take static bone scans of the pelvis and lower limbs three hours after an injection of $555 \mathrm{MBq}$ technetium-99m oxidronate. Scans were reported routinely by one of two nuclear medicine consultants (MAM and CA).

In 1997 the scans of all people referred from the training regiment were retrieved and all identifying information removed. Scans were then reassessed and reported blind by MAM. Scans were classified as abnormal if stress fractures or shin splints were present. To test intraobserver agreement MAM reviewed 50 randomly selected scans four weeks later. Agreement on normality was found in 42 out of 50 cases $(84 \%, \kappa=0.66)$. For interobserver agreement the same scans were assessed by a second consultant (CA) unaware of the patients' identity and previous results. There was agreement in 44 out of 50 cases $(88 \%, \kappa=0.74)$.

A total of 143 men and 121 women were referred with signs and symptoms of lower limb trauma for routine diagnostic radionuclide bone scanning during the study period. The age range was 16-26 (mean 19.5, SD 2.1) for men and 16-30 $(20.1,2.6)$ for women $(P>0.05$ by Student's $t$ test). Nine recruits (three men and six women) were referred twice as a result of repeat injury, resulting in 273 scans.

The table shows the numbers of stress fractures and shin splints in men and women. In all, 71\% (103/146) of scans were abnormal for men and $76 \%(97 / 127)$ for women, suggesting that no significant sex bias exists in the referral pattern $\left(\chi^{2}=1.07 ; \mathrm{P}>0.2\right)$. For the nine subjects who had two scans we classified the results as abnormal if either or both of the scans showed an abnormality. This gave an abnormality rate of $71 \%$ $(101 / 143)$ for men and $77 \%(93 / 121)$ for women.

The rate of referral for bone scanning was $4.2 \%$ (143/3367) for men and 14.2\% (121/855) for women
Incidence of shin splints and stress fractures detected on bone scanning in army recruits

\begin{tabular}{lccccc} 
& Shin splints & Stress fractures & $\begin{array}{c}\text { Other } \\
\text { injury }\end{array}$ & No abnormality & Total referrals \\
\hline Men & $16^{*}$ & $94^{*}$ & 2 & 41 & 146 \\
\hline Women & $8^{*}$ & $92^{*}$ & 3 & 27 & 127 \\
\hline
\end{tabular}

${ }^{*}$ Seven men and three women had both shin splints and stress fractures

(difference $10 \%, 95 \%$ confidence interval $7.5 \%$ to 12.3\%). A two tailed $\chi^{2}$ test with Yates's correction showed that this difference was highly significant $\left(\chi^{2}\right.$ $=112.4, \mathrm{P}<0.001)$. Similarly, the difference in the percentage of male and female recruits with abnormal bone scan results $(3 \%$ (101) men and 10.9\% (93) women; difference $7.9 \%, 5.7 \%$ to $10.0 \%$ ) was highly significant $\left(\chi^{2}=94.7, \mathrm{P}<0.001\right)$.

\section{Comment}

Our results suggest that women are more likely than men to suffer stress fractures during basic training with army training regiments.

We thank the medical staff of Army Training Regiment Winchester who referred the patients for assessment.

Contributors: MAM conceived and initiated the study and wrote the initial draft of the paper. ASH participated in discussion of the core ideas and contributed the experimental design and statistical analysis. LS was responsible for liaising with the training regiment and setting up the experiment. CA took part in discussion of core ideas and participated in the interobserver trials. All authors contributed to writing the paper.

Funding: None.

Conflict of interest: None.

1 Matin P. Bone scintigraphy in the diagnosis and management of traumatic injury. Semin Nucl Med 1983;13:104-22.

2 Holder LE. Radionuclide bone imaging in the evaluation of athletic injuries. Curr Concep Diagn Nucl Med 1985;2:3-8.

(Accepted 3 September 1998)

\section{Corrections}

Training in plastic surgery is being set up in the Gambia

In this letter (18 April, p 1244) the surname of the first author was spelt incorrectly. It was given as Ian F Stanley but is in fact Ian F Starley. The name of the second author (Paul Mohammed) was given correctly.

Tight blood pressure control and risk of macrovascular and microvascular complications in type 2 diabetes: UKPDS 38

In figure 9 of this paper by the UK Prospective Diabetes Study Group (12 September, p 703-13) the final two headings in the left hand column ("abnormal Q, ST, or T waves in electrocardiogram" and "abnormal $\mathrm{Q}$ waves in electrocardiogram") were interchanged. With the headings in their correct positions, the data are correct.

\section{Department of Nuclear Medicine, Royal Hospital Haslar, Gosport, Hampshire PO12 2AA M A Macleod, consultant in nuclear medicine \\ A S Houston, consultant medical physicist L Sanders, medical physics technician \\ C Anagnostopoulos, consultant in nuclear medicine \\ Correspondence to: Dr Macleod murdo@haslar. demon.co.uk \\ BMJ 1999;318:29}

